\title{
Global Futures: Building Interdisciplinary Postdoctoral Research Careers
}

\author{
Rebecca Vipond* \\ The Institute of Advanced Study, University of Warwick \\ *Correspondence: R.Vipond@warwick.ac.uk
}

\begin{abstract}
On 19 and 20 May 2016 the Institute of Advanced Study convened a two-day conference entitled Global Futures: Building Interdisciplinary Postdoctoral Research Careers. This symposium was attended by 100 postgraduate students, postdoctoral researchers and early career academics from across the University of Warwick. Seven workshops throughout the two days covered current sources of funding, testimony on building a successful research career, developing an excellent academic track record, engaging with non-academic audiences, and advice on writing successful proposals. Additionally nine attendees competed in a flash talk competition, where they were challenged to speak for five minutes each about the core message of their research.
\end{abstract}

Keywords: Fellowship, Funding, Symposium, Postdoctoral Training,

Funding: See page 152

Peer review: This article has been subject to a double blind peer review process

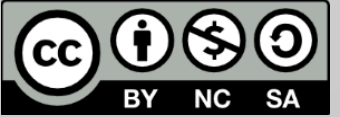

(C) Copyright: The Authors. This article is issued under the terms of the Creative Commons Attribution NonCommercial Share Alike License, which permits use and redistribution of the work provided that the original author and source are credited, the work is not used for commercial purposes and that any derivative works are made available under the same license terms.
Interdisciplinary

The postdoctoral community live in an ever more competitive world (Else, 2015; Benderly, 2015). With funding for academic projects in all disciplines having been reduced in recent years (Ahmed, 2016), the pressure on Early Career Researchers (ECRs) to build an excellent track record from an early juncture is great (Patton, 2014). Universities have to respond to this challenge by increasing support and training for postdoctoral researchers (Academics Anonymous: so many PhD Students, so few Jobs, 2014). There is a growing need for specific and tailored information and training to be available to those attempting to launch their independent careers in academia (Brownell, 2012). In particular, advice must be available on the practical ways to become a more competitive applicant in the academic employment market (Huang, 2015; Powell, 2015). A postgraduate attendee at the recent Institute of Advanced Study (IAS) symposium said, 'it would have been useful to know the expectations for post-doc and Fellowship applications at an earlier date so they could be worked on consistently throughout the course of study.' 
On 19 and 20 May 2016, the IAS convened a two-day symposium entitled Global Futures: Building Interdisciplinary Postdoctoral Research Careers, aimed at the ECR community at the University of Warwick. The IAS Director, Professor Giorgio Riello, began by introducing the purpose of the symposium. This was to provide support for postdoctoral researchers at a difficult transitional moment in their careers with practical advice and testimony on the different aspects of building and presenting a wellrounded and successful career in research.

The first session brought speakers from four academic funding bodies the British Academy, the Engineering and Physical Sciences Research Council, the Royal Society and the Wellcome Trust - together to discuss their current funding opportunities and the characteristics an 'ideal' Fellowship candidate would possess. Although the funding bodies represented the full range of academic disciplines, many of the desirable traits they described were identical. Fellowship funding is foremost about supporting preeminent young researchers in their respective fields; Fellowship holders are anticipated to be taking on permanent faculty positions after completing their awards. Successful candidates demonstrate academic excellence with a well-defined and substantial portfolio of outputs. They will also show their independence, leadership, originality and innovation. Each of these key qualities is assessed through the curriculum vitae and funding proposal, with a short list of candidates being invited to interview before successful applicants are awarded Fellowships. This particular funding route is of course extremely competitive, with most Fellowship schemes having a $5-20 \%$ success rate.

The next sessions considered how ECRs can build a record of the attributes that Fellowship funders look for. Two established international professors, Pamela Gilbert (University of Florida) and Sandra Vasconcelos (University of Sao Paulo), were visiting the University of Warwick, supported by IAS International Visiting Fellowships. They spoke about their experiences building research careers in the USA and Brazil, systems which present similar challenges and rewards to academia in the UK and Europe. A key message from these speakers was the importance of articulating the broader impact of academic work. During the progression from being a very junior to a more established member of a research field, being able to communicate how individual research projects fit into the wider community will be vital, and will always help to answer the question 'why should we care about your research?' It is vital to be able to communicate the key challenges and findings of any research project in an effective and succinct way to a non-specialist audience. The International Visiting Fellows also gave testimony on the importance of personal time management. This can be a substantial challenge, 
especially associated with the progression to more senior roles that have greater administration and teaching responsibilities on top of multiple research projects.

IAS Global Research Fellows Dr James Sprittles (Mathematics Institute), Dr Julie Walsh (Department of Sociology) and Dr Gemma-Louise Davies (Department of Chemistry) discussed some of the tactics that they had used in building their independent research careers. Participating actively in research networks can bring varied opportunities, such as being invited to give talks or set up new collaborations, and building up administration experience, alongside organising workshops and seminars. Actively building a track record from an early stage is vital. At the point of applying for a Fellowship it is important to be able to evidence the following: an excellent publication portfolio, including first and sole author papers; the ability to win funding - even small amounts such as travel bursaries will add weight; national or international recognition, for example by being invited to present seminars and papers; and teaching and committee work. This was summarised by Rachel Corke (The Petroleum Institute, Abu Dhabi). The most competitive applicants can demonstrate their vision through creative, proactive and productive means. One attendee noted that 'it is important "to have a plan before you think you need a plan"'.

The first day of the symposium closed with a flash talk competition. Nine postdoctoral researchers from across all four University Faculties gave five minute talks, where they summarised the central argument to their research projects. Each talk was supported by a single image. The talks ranged from using modified carbon nanotubes in tiny computers to the ethics of women's labour in Turkish tomato factories. A panel of five judges convened to award a first and two runner-up prizes to the speakers that, along with giving an exemplary performance, spoke to the core aim of the IAS - namely championing interdisciplinary postdoctoral research.

The second day of the symposium began with a discussion of what is considered the central standard of academic esteem - publications. Professors Richard Aldrich (Department of Politics and International Studies) and Christopher Warhurst (Institute for Employment Research) gave advice on taking a thoroughly strategic approach to building a publication record. One attendee was keen to learn about 'the importance of publishing in good journals and how this affects your ability to apply for grants'. Publication strategies can vary greatly by discipline and so the speakers noted the importance of becoming familiar with how publication records are built in different subject areas and, perhaps just as importantly, what types of publication may not add value 
to an academic track record. Proactively creating a two to five year publication plan is one method of tackling this challenge. By setting specific aims, such as target journals or publishers, and objectives, such as collaborations and timelines, the scheme of work being carried out is given a coherent direction. Additionally ECRs need to consider the creation of first and sole author works from a very early stage. This is arguably the best way to demonstrate independence, a vital attribute to winning grant and Fellowship funding.

Dissemination through public engagement and the consideration of the potential economic, environmental and societal impact of research is an increasingly important focus to many research funding bodies (Research Councils UK, 2014). Therefore, ECRs need to consider how current and future projects could benefit wider society, rather than focussing only on academic impact. In the penultimate session speakers gave examples of the different ways that they engage with non-academic audiences and how ECRs can use these types of interaction to drive innovative approaches to their own research. Trevor Power (Warwick Ventures) discussed the different ways to develop new commercial products and intellectual property from the outcomes and methodology of different research projects. Warwick Ventures exists to aid this process for academics at the University of Warwick. Dr Christopher Kay (Department of Chemistry) exemplified the commercialisation of his research in polymer chemistry with testimony of his experiences setting up a spinout company using Innovation to Commercialisation of University Research (ICURe) grant funding. Clare Siviter (Department of Modern Languages and Cultures) gave several examples of disseminating her research on Napoleon to school children through interactive outreach activities. She also discussed the concept of using children as researchers and a source of new ideas. Dr Mike Chappell (School of Engineering) and Dr Magdalena Skrybant (Warwick Medical School) spoke about their work in public engagement through medical research. By engaging with end users - from medical patients, commercial customers, to school pupils - throughout their research projects, each speaker demonstrated how their work had been positively influenced by the consideration of and feedback from different non-academic groups, as well as benefitting the economy, environment and society.

The final session of the symposium considered the practicalities of crafting excellent grant and Fellowship proposals. Dr John Burden (Institute of Advanced Study) gave advice on the elements that constitute a good (and bad) application. This was substantiated by two current Fellowship holders - Dr Simone Varriale (Leverhulme Early Career Fellow, Department of Sociology) and Dr Peter Gammon (RAEng Fellow, Department of Engineering). When considering a funding application of 
any type, after determining the eligibility criteria are satisfied, it is important to remember that every funding scheme has a purpose; what is the funding body trying to achieve? In the case of preparing a Fellowship application, the most important facet is the person: an outstanding candidate who demonstrates independence, commitment, originality and a track record of academic excellence. The second most important element to consider is the place in which the Fellowship will be held: where the best and most appropriate facilities and support in a particular institution will be available, reinforced by letters of support. The third most important component is crafting the research project proposal itself: being ambitious whilst mitigating potential risks, showing scope for the development new research skills, and having concrete plans for the delivery of academic, societal and economic outputs. $\mathrm{Dr}$ Burden finished by giving a list of six golden rules for writing funding applications: always read the supporting documentation (e.g. funding guidelines etc.); check compatibility with the eligibility criteria; allow enough time to complete the application as funder deadlines are nonnegotiable; craft a well written prose in language that is understandable to a non-expert; emphasise how the proposal matches the funder mission statement; and take advice from current award holders and senior colleagues.

Professor Giorgio Riello closed the symposium by reiterating that while the postdoctoral community are in an increasingly competitive environment, the route to successful funding bids and building a career in research relies on hard work rather than pure luck. By taking advantage of opportunities that arise and actively developing an accomplished academic track record, it is certainly possible to build a thriving interdisciplinary postdoctoral research career. The key messages from the speakers at Global Futures: Building Interdisciplinary Postdoctoral Research Careers were: take a strategic approach to an excellent and forward focussed publication record which demonstrates independence; engage actively with a large network of colleagues to establish new collaborations and scope an innovative research outlook; maximise the impact of any research findings through communication and public engagement; and allow the time to craft each of these elements in order to compose a precise and accomplished grant, fellowship or job application.

The symposium was well received by the audience of 100 postgraduate and postdoctoral researchers. One attendee said, 'it was very useful to listen to people who succeeded in their academic careers. The most interesting and helpful theme for me as a postdoc was the one about writing Fellowship applications.' Another attendee said, 'firstly, it made me focus on my potential academic career as a whole, rather than just 
thinking about my current research. Secondly, it has helped me to identify what areas I need to work on if I am to successfully apply for a Fellowship in the future.' Full details of the symposium programme and speaker presentations are available at www.warwick.ac.uk/globalfutures.

\section{Acknowledgement}

I would like to extend my thanks to the Institute of Advanced Study, University of Warwick for sponsoring the conference. I would also like to thank all of the invited speakers and panel chairs for their excellent contributions and my colleagues for their help in convening the conference. In particular I would like to thank the speakers from the external funding bodies: British Academy, EPSRC, the Royal Society and the Wellcome Trust. Finally, my congratulations to the winners of the flash talk competition.

\section{References}

M. Z. Ahmed (2016), Opinion: The Postdoc Crisis, http://www.thescientist.com/?articles.view/articleNo/44874/title/Opinion--The-PostdocCrisis/, accessed 6 June 2016.

Anonymous (2014), Academics Anonymous: so many PhD Students, so few Jobs, http://www.theguardian.com/higher-educationnetwork/blog/2014/may/23/so-many-phd-students-so-few-jobs, accessed 6 June 2016.

Benderly, B. L. (2015), The not-quite-stated, awful truth, http://www.sciencemag.org/careers/2015/01/not-quite-stated-awfultruth, accessed 6 June 2016.

Brownell, S.E. and Tanner, K. D. (2012), CBE - Life Sciences Education, 11, 339-46, http://www.ncbi.nlm.nih.gov/pmc/articles/PMC3516788/.

Else, H. (2015), The Postdoc Experience: Hopes and Fears, https://www.timeshighereducation.com/the-postdoc-experience-hopesand-fears, accessed 6 June 2016.

Huang, B.L. (2015), How postdocs can maximise their career chances in a competitive world, https://www.elsevier.com/connect/how-postdocscan-maximize-their-career-chances-in-a-competitive-world, accessed 6 June 2016. 
Patton, S. (2014), Between Postdoc and a Job, a Whole Lot of Questions, https://chroniclevitae.com/news/632-between-postdoc-and-job-awhole-lot-of-questions, accessed 6 June 2016.

Powell, K. (2015) the future of the postdoc', Nature, 520, 144-47 http://www.nature.com/news/the-future-of-the-postdoc-1.17253, accessed 6 June 2016.

Research Councils UK, Research Councils UK Impact Report 2014 (2014), http://www.rcuk.ac.uk/documents/publications/2014impactreport-pdf/, accessed 19 July 2016.

\section{To cite this article:}

Kaner, R. (2016). Global Futures: Building Interdisciplinary Postdoctoral Research Careers. Exchanges: The Warwick Research Journal, 4(1), 140-146. Retrieved from:

http://exchanges.warwick.ac.uk/index.php/exchanges/article/view/114 